\title{
CORROSION INHIBITION OF LOW CARBON STEEL IN SIMULATED WASTEWATER FROM PETROLEUM INDUSTRY
}

\author{
JULIETA DANIELA CHELARUa, DOVRAN AYLAKOV', \\ LIANA MARIA MUREŞAN ${ }^{\mathrm{a} *}$
}

\begin{abstract}
The corrosion inhibition efficiency of three commercial inhibitors on low carbon steel was investigated by electrochemical methods (EIS and polarization curves). The efficiency of corrosion inhibitors was tested at different concentrations. Corrosion tests were carried out in a solution simulating a saline wastewater from petroleum industry $(\mathrm{pH}=3)$ in order to find the best inhibitor for the protection of steel pipelines.
\end{abstract}

Key words: steel, corrosion inhibitors, electrochemical impedance spectroscopy, polarization curves, inhibitor efficiency, synthetic wastewater from petroleum industry.

\section{INTRODUCTION}

The corrosion of pipelines from petrochemical industry can lead to decreased production, economic losses and also security risks [1]. Pipelines corrosion can be caused by a wide variety of factors, including physical, chemical and biological ones [2]. Almost any aqueous environment can promote corrosion, which occurs under numerous complex conditions in oil and gas production, processing, and pipeline systems [3].

Water is frequently injected into wells to increase oil recovery. There is referred to as produced water, and is the largest volume by product stream in oil and gas production, having an adverse environmental impact due to its complex composition and high disposal costs. The cost of producing, handling, and disposing of the produced water often defines the economic lifetime of an oil field and the actual hydrocarbon reserves; therefore, understanding and predicting the aspects, behavior, and problems induced by the produced-water flow is important.

a "Babeş-Bolyai" University, Department of Chemical Engineering, 11 Arany Janos St., 400028 Cluj-Napoca, Romania

${ }^{*}$ Corresponding author: limur@chem.ubbcluj.ro 
The composition of produced water is complex. The major hydrocarbon groups present in produced water include alkanes, aromatics, polynuclear aromatics, hydrocarbon compounds containing oxygen, nitrogen and sulfur and unknown hydrocarbons (oil \& grease) [4 - 6]. Produced water also contains high amounts of dissolved salts with predominant cations such as $\mathrm{Na}^{+}, \mathrm{K}^{+}, \mathrm{Ca}^{2+}$ and $\mathrm{Mg}^{2+}$; anions such as $\mathrm{Cl}^{-}$and $\mathrm{SO}_{4}{ }^{2-}$, and silica $\left(\mathrm{SiO}_{2}\right)$ [6].

Due to its composition, produced water is a highly corrosive medium for the steel pipelines. In order to prevent their corrosion, the first priority is to find the factors that lead to corrosion and after that, to use the most appropriate methods of corrosion protection.

The use of inhibitors is one of the most practical methods for protecting metals or alloys from corrosion [7]. There is a wide variety of organic compounds used as corrosion inhibitors for steel in acid media: amines [8], compounds based on imidazoline [9], triazoles, pyridine [10], aromatic aldehydes, but also "green compounds" such as henna extract [11], Justicia gendarussa plant extract [12] etc., but to find new efficient corrosion inhibitors remains a challenge.

In this context, the aim of this paper is to investigate the corrosion of low carbon steel in synthetic solutions simulating wastewater from petroleum and oil industry $(\mathrm{pH} 3)$ in the absence and in the presence of two commercial phosphino succinic oligomer derivatives from Nalco Products, USA, (3DT177, 3DT179). They inhibit calcium carbonate scale formation and are used in a variety of cooling water applications in many industries. The effect of these inhibitors was compared with that of Galoryl IC20 (produced by ArrMazz Chemicals SAS, USA).

The protective effect of inhibitors at different concentrations was investigated by electrochemical methods (polarization measurements and electrochemical impedance spectroscopy).

\section{RESULTS AND DISCUSSION}

\section{Polarization measurements}

In order to characterize the protective effect of the inhibitors at different concentrations in the synthetic wastewater $(\mathrm{pH}=3)$, electrochemical corrosion measurements were carried out.

The evolution of the open circuit potential (OCP) of the low carbon steel was recorded, in the absence and in the presence of corrosion inhibitors, during 1 hour (Fig. 1). Analyzing the data it can be observed a positive shift of OCP values in the presence of inhibitors, but no clear correlation was found between the OCP and the inhibitors concentration. 

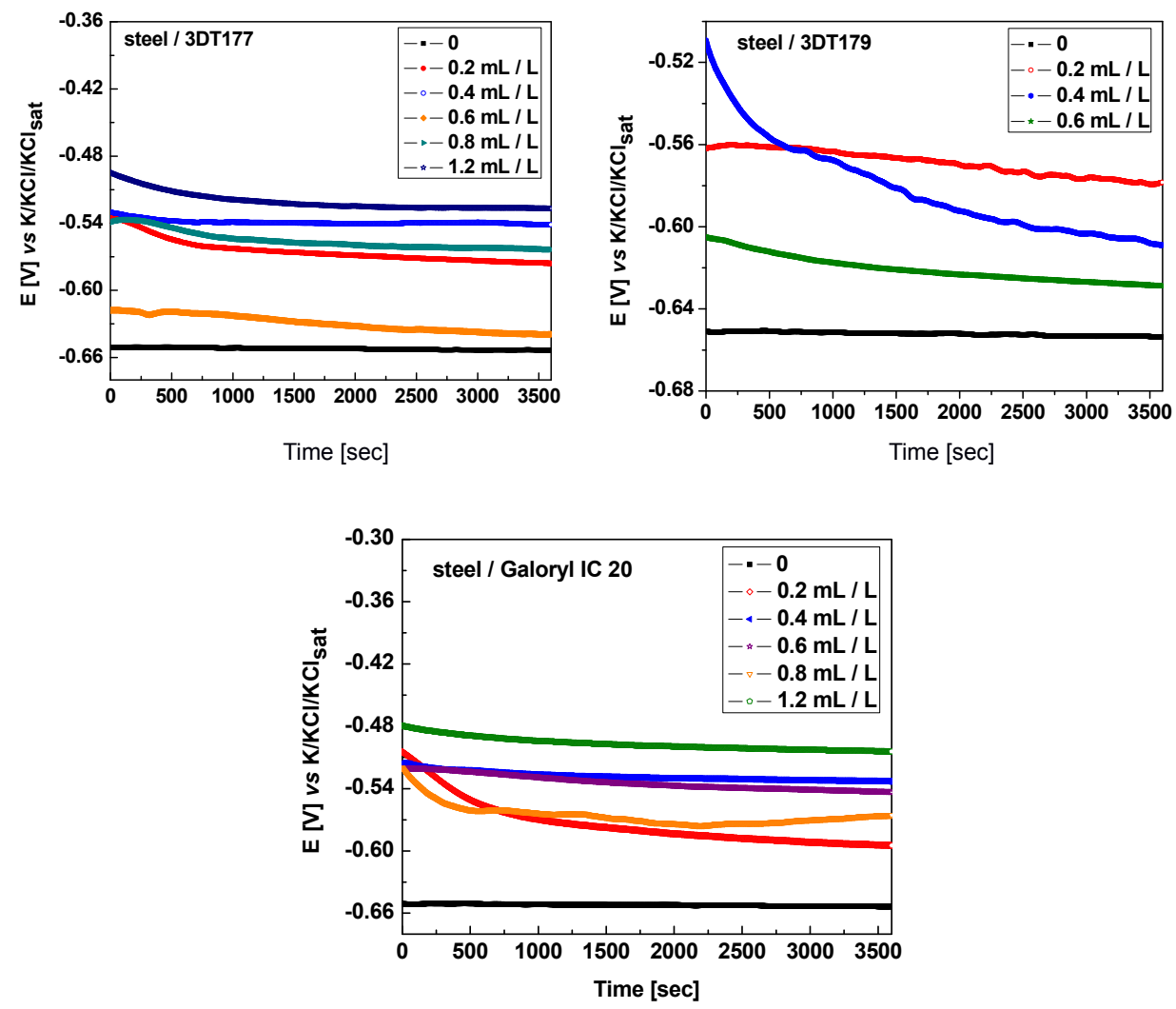

Figure 1. Open circuit potential measurements for the tested samples in the presence of corrosion inhibitors, immersed in corrosion solution, $\mathrm{pH} 3$

\section{Electrochemical impedance spectroscopy}

Impedance spectra were recorded immediatly after OCP monitoring in the simulated produced water in the presence of various concentrations of inhibitors and the results obtained were compared with those without inhibitors.

The Nyquist diagrams for steel corrosion in the presence of 3DT177 and Galoryl IC 20 are presented in Fig. 2. It can be observed that the impedance spectra exhibit a capacitive behaviour in the whole frequency domain. The experimental impedance spectra were analyzed for all cases by fitting to a $2 R Q$ equivalent electrical circuit (Fig. 3). The parameters obtained for all samples by using the proposed equivalent electrical circuits are shown in Table 1 . The quality of fitting procedure was evaluated by the chi squared $\left(X^{2}\right)$ values, which were of order $10^{-4}$. 
The equivalent electrical circuit from Fig. 3 consists of: the $R_{c t}-C_{d l}$ couple at high frequencies, representing the charge transfer resistance $R_{c t}$ and the double layer capacity, $\mathrm{C}_{\mathrm{dl}}$, at the steel | electrolyte interface and a second couple $\left(R_{F}-C_{F}\right)$ at low frequencies, where $R_{F}$ represents the faradic resistance of the corrosion products accumulated at the interface and $\mathrm{C}_{\mathrm{F}}$, the faradic capacity due to an oxidation - reduction process taking place at the electrode surface, probably involving the corrosion products. $R_{e}$ represents the electrolyte resistance. Coefficients $n_{d l}$ and $n_{F}$ represent the depressed feature of the capacitive loop in Nyquist diagram $(0<n \leq 1)$. The values of $C_{F}$ and $C_{d l}$ were calculated using the equation $C=\left(R^{1-n} Q\right)^{1 / n}$, where $Q$ is the constant phase element.
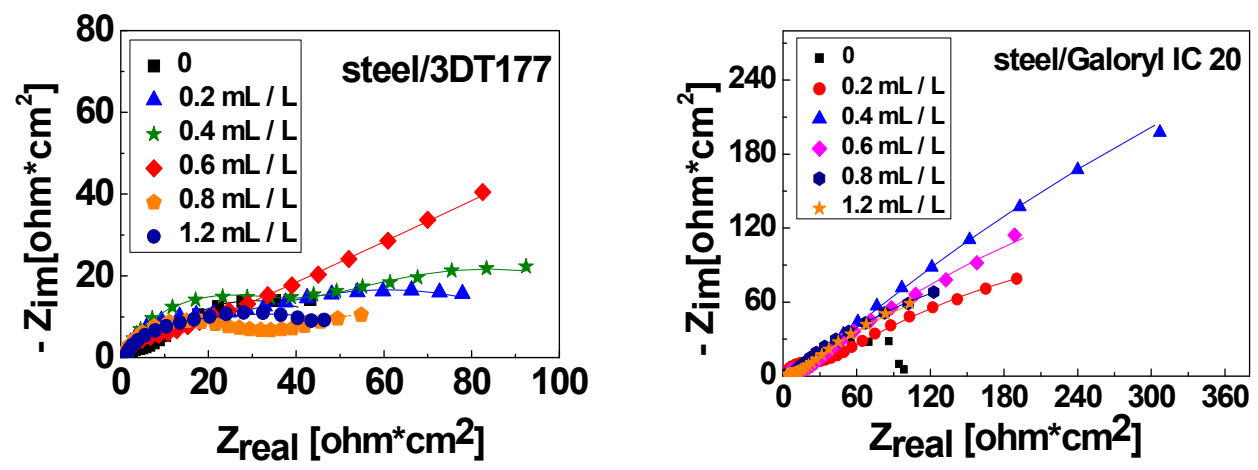

Figure 2. Nyquist impedance diagrams for the steel electrodes in synthetic wastewater ( $\mathrm{pH} 3)$, at diferent concentrations of inhibitors; the lines represent fitted data

Analyzing the data from Table 1, it can be observed that, the value of the corrosion resistance depends on the concentrations of inhibitors, which influences the formation of the oxide film which inhibits the corrosion process on the surface of steel. 


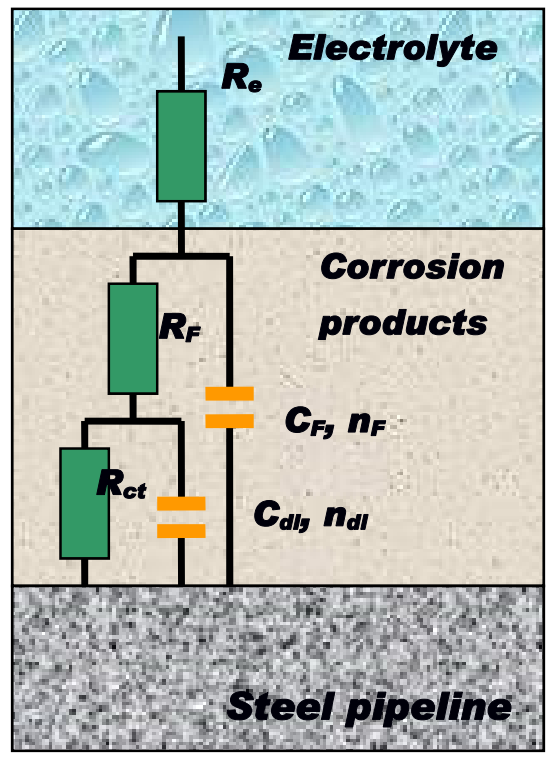

Figure 3. The equivalent electrical circuit used for fitting of the experimental results

Table 1. The electrochemical impedance parameters estimated by fitting the experimental impedance data from Figure 6.

\begin{tabular}{|c|c|c|c|c|c|c|c|c|c|}
\hline & $\begin{array}{c}\text { Concentration } \\
{[\mathrm{mL} / \mathrm{L}]}\end{array}$ & $\begin{array}{c}R_{\mathrm{e}} \\
{\left[\Omega^{*} \mathrm{~cm}^{2}\right]}\end{array}$ & $\begin{array}{c}\mathbf{R}_{\mathrm{ct}} \\
{\left[\Omega^{*} \mathrm{~cm}^{2}\right]}\end{array}$ & $\begin{array}{c}\mathrm{C}_{\mathrm{dl}} \\
{\left[\mu \mathrm{F} / \mathrm{cm}^{2}\right]}\end{array}$ & $n_{d \mathbf{l}}$ & $\begin{array}{c}R_{\mathbf{F}} \\
{\left[\Omega^{*} \mathrm{~cm}^{2}\right]}\end{array}$ & $\begin{array}{c}\mathrm{C}_{\mathrm{F}} \\
{\left[\mathrm{mF} / \mathrm{cm}^{2}\right]}\end{array}$ & $\mathrm{n}_{\mathrm{F}}$ & $\begin{array}{c}R_{p}{ }^{*} \\
{\left[\Omega^{*} \mathrm{~cm}^{2}\right]}\end{array}$ \\
\hline & 0 & 1.55 & 11.15 & 215.5 & 0.804 & 97.9 & 19.23 & 0.648 & 109.03 \\
\hline \multirow{5}{*}{ 点 } & 0.2 & 1.80 & 71.51 & 321.2 & 0.804 & 200.6 & 51.77 & 0.492 & 272.11 \\
\hline & 0.4 & 1.56 & 27.90 & 165.9 & 0.775 & 289.8 & 52.55 & 0.501 & \begin{tabular}{|l|}
317.70 \\
\end{tabular} \\
\hline & 0.6 & 1.73 & 26.84 & 132.5 & 0.851 & 276.2 & 44.17 & 0.230 & 303.04 \\
\hline & 0.8 & 1.67 & 35.08 & 177.6 & 0.884 & 179.2 & 21.60 & 0.435 & \begin{tabular}{|l|}
214.28 \\
\end{tabular} \\
\hline & 1.2 & 2.03 & 24.01 & 369.4 & 0.807 & 110.8 & 15.25 & 0.401 & 134.81 \\
\hline \multirow{5}{*}{$\begin{array}{l}\bar{N} \\
\underline{N} \\
\bar{X}\end{array}$} & 0.2 & 1.6 & 19.9 & 39.75 & 0.85 & 659.8 & 307.5 & 0.38 & 679.7 \\
\hline & 0.4 & 2.93 & 10.11 & 18.52 & 0.79 & 2045 & 251.5 & 0.46 & 2055.11 \\
\hline & 0.6 & 2.19 & 11.47 & 17.65 & 0.84 & 952.4 & 311 & 0.44 & 963.87 \\
\hline & 0.8 & 1.10 & 3.63 & 2.72 & 0.65 & 466.8 & 263.9 & 0.45 & 470.43 \\
\hline & 1.2 & 2.37 & 8.83 & 17.87 & 0.46 & 445.3 & 399.4 & 0.46 & 454.13 \\
\hline
\end{tabular}

$\mathbf{R}_{\mathbf{p}}{ }^{*}=\mathbf{R}_{\mathrm{ct}}+\mathbf{R}_{\mathbf{F}}$

The highest polarization resistance $\left(\mathbf{R}_{\mathbf{p}}=\mathbf{R}_{\mathrm{ct}} \mathbf{+} \mathbf{R}_{\mathbf{F}}\right)$, which is an indicator of corrosion resistance, was observed at the concentration of $0.4 \mathrm{~mL} / \mathrm{L}$. From the three tested inhibitors, Galoryl IC 20 was proven to be the best. The results were confirmed by linear and potentiodynamic polarization measurements. 

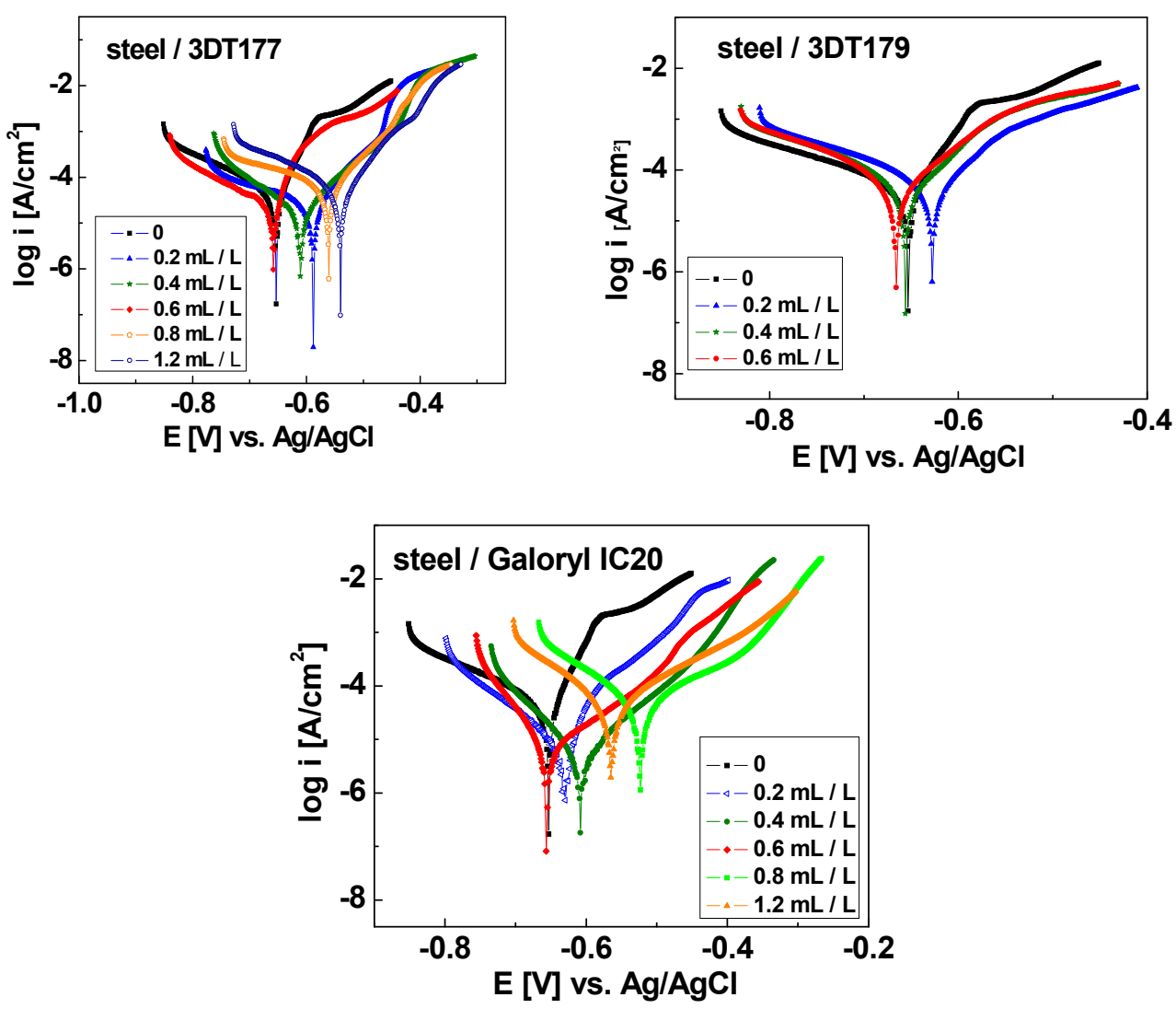

Figure 4. The polarization curves $( \pm 200 \mathrm{mV} v$ s. OCP $)$ for the studied electrodes immersed in synthetic wastewater $(\mathrm{pH}=3)$ at different concentrations of inhibitors; scan rate, $10 \mathrm{mV} / \mathrm{min}$.

To determine the polarization resistance of the electrodes, linear polarization curves were recorded, in the potential domain of $\pm 20 \mathrm{mV} v s$. OCP. The polarization resistance $\left(R_{p}\right)$ values, for each electrode, was calculated with the formula: $R_{p(\Delta E \rightarrow 0)}=\frac{\Delta E}{\Delta i},(1)$, and are shown in Table 2 . The protection efficiency of the inhibitors on steel was determined with the formula: $\quad I E[\%]=\frac{R_{p}^{i n h}-R_{p}^{0}}{R_{p}^{i n h}} \cdot 100,(2)$, where $\mathrm{R}_{\mathrm{p}}{ }^{\text {inh }}$ is the polarization resistance in presence of inhibitors and $R_{p}{ }^{0}$ is the polarization resistance without inhibitors, respectively. 
In order to determine the kinetic parameters of the corrosion process, potentiodynamic polarization curves were recorded in the potential range of \pm $200 \mathrm{mV}$ vs. OCP (Fig. 4). The Tafel interpretation of the polarization curves led to the results presented in Table 2.

Table 2. Corrosion process parameters for the examined samples

\begin{tabular}{|c|c|c|c|c|c|c|c|}
\hline Inhibitor & $\begin{array}{c}\text { Concentration } \\
{[\mathbf{m L} / \mathbf{L}]}\end{array}$ & $\begin{array}{c}\mathbf{E}_{\text {corr }} \\
{[\mathbf{m V}]}\end{array}$ & $\begin{array}{c}\mathbf{i}_{\text {corr }} \\
{\left[\mathbf{\mu A} / \mathbf{c m}^{2}\right]}\end{array}$ & $\begin{array}{c}-\boldsymbol{\beta}_{\mathbf{c}} \\
{[\mathbf{m V}]}\end{array}$ & $\begin{array}{c}\boldsymbol{\beta}_{\mathbf{a}} \\
{[\mathbf{m V}]}\end{array}$ & $\begin{array}{c}\mathbf{R p} \\
{\left[\mathbf{\Omega}^{*} \mathbf{c m}^{2}\right]}\end{array}$ & $\begin{array}{c}\text { IE } \\
{[\%]}\end{array}$ \\
\hline- & 0 & -654.34 & 61.80 & 166.79 & 46.36 & 80 & - \\
\hline \multirow{4}{*}{ 3DT177 } & 0.2 & -587.81 & 38.38 & 447.07 & 84.40 & 570 & 84.04 \\
\cline { 2 - 8 } & 0.4 & -613.35 & 18.36 & 145.87 & 103.16 & 970 & 86.61 \\
\cline { 2 - 8 } & 0.6 & -658.06 & 24.46 & 155.38 & 36.87 & 480 & 84.38 \\
\cline { 2 - 8 } & 0.8 & -558.11 & 86.09 & 401.05 & 110.99 & 400 & 74.14 \\
\hline \multirow{3}{*}{ 3DT179 } & 1.2 & -541.08 & 74.06 & 186.23 & 84.12 & 280 & 74 \\
\cline { 2 - 8 } & 0.2 & -627.44 & 73.45 & 180.60 & 82.81 & 90 & 16 \\
\cline { 2 - 8 } & 0.4 & -655.14 & 60.51 & 140.29 & 80.28 & 90 & 16 \\
\hline \multirow{4}{*}{\begin{tabular}{c} 
Galoryl \\
\cline { 2 - 8 }
\end{tabular}} & 0.6 & -665.63 & 60.38 & 135.18 & 89.61 & 110 & 31.81 \\
\cline { 2 - 8 } & 0.2 & -628.58 & 7.18 & 105.54 & 48.00 & 450 & 83.33 \\
\cline { 2 - 8 } & 0.4 & -607.73 & 5.75 & 78.75 & 132.13 & 580 & 87.07 \\
\cline { 2 - 8 } & 0.6 & -636.34 & 9.59 & 62.81 & 114.91 & 380 & 80.26 \\
\cline { 2 - 8 } & 0.8 & -521.64 & 48.86 & 115.87 & 142.83 & 340 & 77.94 \\
\hline
\end{tabular}

$\beta_{\mathrm{a}}$ and $\beta_{\mathrm{c}}$ are the Tafel coefficients [mV]

The analysis of the data from Table 2 led to the conclusion that in case of 3DT177 and Galoryl IC 20 an increase of corrosion resistance takes place at all inhibitors concentrations. The highest corrosion resistance and the lowest corrosion current density were noticed at $0.4 \mathrm{~mL} / \mathrm{L}$ concentration of inhibitors. This is in agreement with the results obtained from the EIS measurements. significant.

In case of 3DT179, the increase of the corrosion resistance was not

\section{Adsorption isotherm}

The polarization resistance values (Table 2), were used to calculate the degree of surface coverage $(\theta)$ with inhibitor molecules according to the following equation: $\theta=\frac{R_{p}^{i n h}-R_{p}^{0}}{R_{p}^{i n h}},(3)$. 
Since the corrosion inhibition process is based on the adsorption of corrosion inhibitor molecules on steel surface, it is important to elucidate their adsorption behaviour. Fig. 5 shows that the plot of $\frac{C_{i n}}{\theta}$ versus $C_{i n}$ results in a straight line, confirming that the adsorption of both inhibitors (3DT177 and Galoryl IC20) on low carbon steel obeys Langmuir isotherm: $\frac{C_{i n}}{\theta}=\frac{1}{K}+C_{i n}$, (4) where $\mathrm{K}$ is the adsorption equilibrium constant and $C_{\text {in }}$ is the inhibitor concentration.

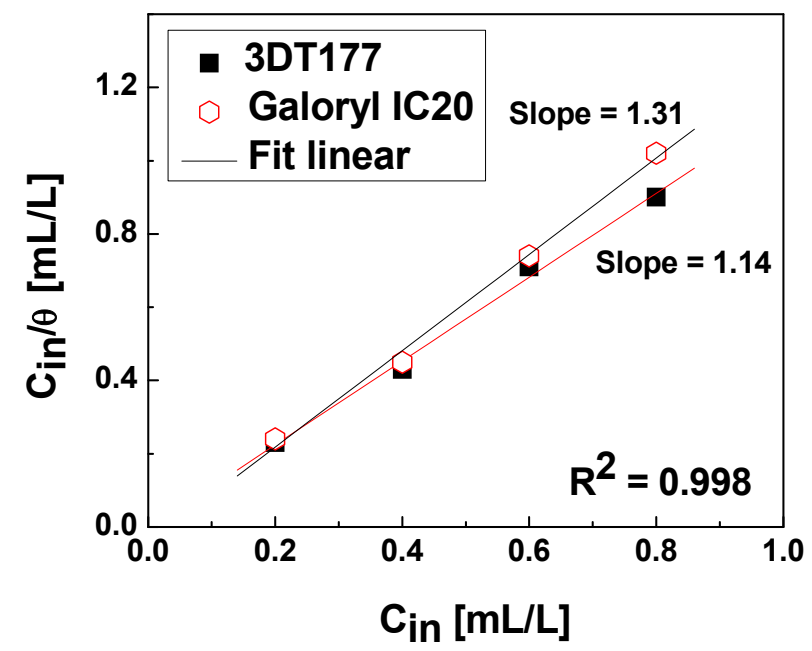

Figure 5. Langmuir isotherm for adsorption of 3DT177, Galoryl IC 20 on low carbon steel surface

The beneficial effect of Galoryl IC 20 can be seen also by naked eye, inspecting the steel electrodes surface after the corrosion tests. As can be observed from Fig. 6, in the absence of inhibitors, the surface is nonuniformly corroded. In the presence of 3DT177, the surface is covered with a uniform layer of corrosion products which may confer to steel a certain resistance to further corrosion. Best results were obtained in the case when Galoryl IC 20 was used, the electrode surface remaining clean and bright after the corrosion tests. 


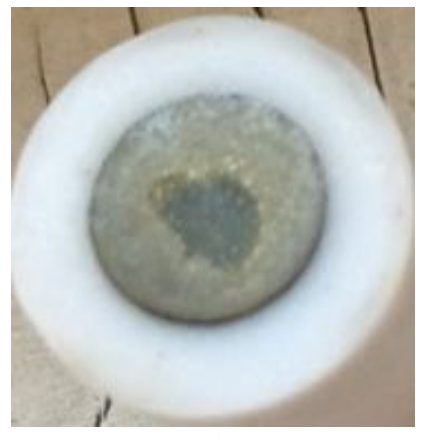

a)

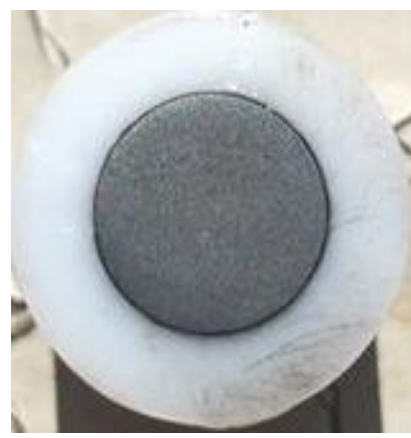

b)

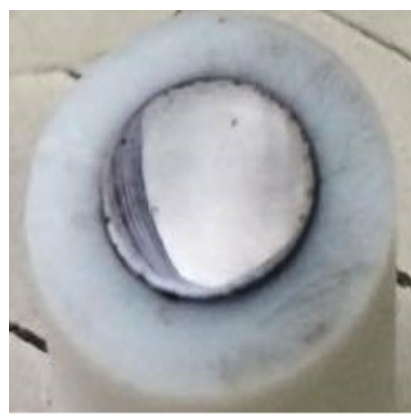

c)

Figure 6. Surface of low corbon steel electrodes after corrosion tests: in the absence of inhibitors (a), in the prezence of 3DT177 (b) / Galoryl IC 20 (c)

\section{CONCLUSIONS}

Electrochemical investigations (polarization and impedance measurements) have shown that two of the three inhibitors used exert a good protective effect against steel corrosion in simulated wastewater from petroleum and oil industry. The best anticorrosive effect was noticed when $0.4 \mathrm{~mL}$ inhibitor were used (PE $=86.61 \%$ for 3DT177 and respectively PE $=87.07 \%$ for Galoryl IC 20). With the increase of inhibitors concentration in corrosion solution, the anticorrosive effect in both cases decreases.

The corrosion behavior of the steel immersed in synthetic wastewater from petroleum and oil industry $(\mathrm{pH} 3)$ solution can be simulated with a $2 \mathrm{RQ}$ electric circuit.

Adsorption of both inhibitors (3DT177, Galoryl IC 20) on low carbon steel surface obeys Langmuir isotherm.

\section{EXPERIMENTAL}

\section{Materials}

The working electrodes used in this work were cut from an OL37 steel bar, with the chemical composition (wt. \%): C (0.22), Mn (0.85), P (0.055), $S(0.055)$ and Fe balance. The surface of the working electrodes exposed to the corrosive solution was disk - shaped, with a surface $S=0.5$ $\mathrm{cm}^{2}$. The working electrodes were sealed by encapsulation in Teflon. For electrical contact, a copper rod was attached. Before the corrosion tests, the working surface of the electrodes was ground sequentially with emery papers from \# 800 up to \# 2000 grades, and degreased with acetone, washed with 
distilled water and dried. The surface of the steel electrodes was examined by optical microscopy using an OLIMPUS GS 51 optical microscope. For this purpose, the electrodes were polished on the sample polishing machine with alumina paste, after which the surface was attacked with nital for a few seconds. The microstructure of the steel contained ferrite and pearlite (Fig. 7).

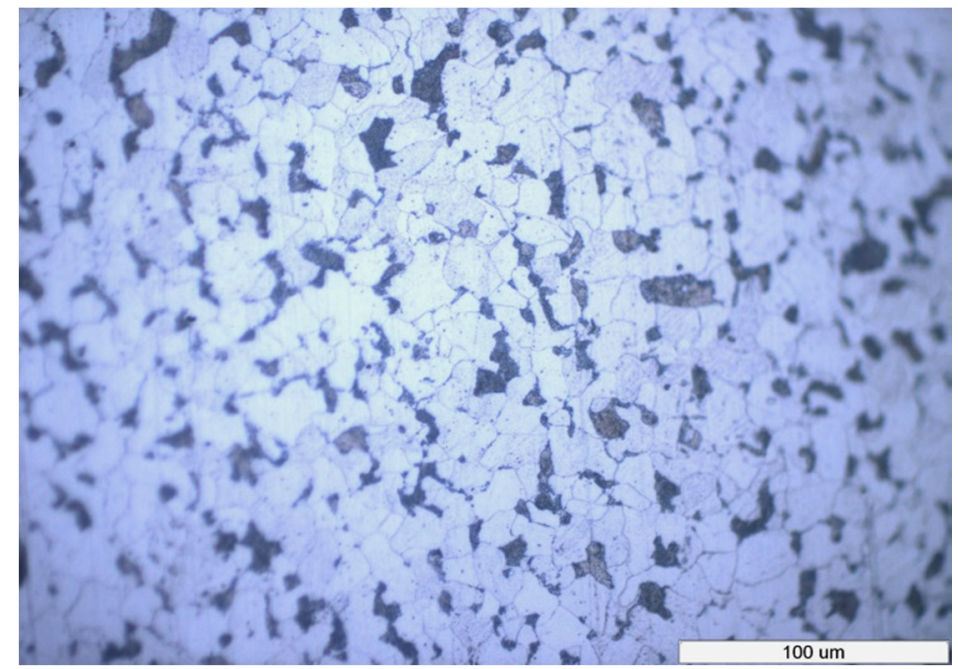

Figure 7. Microscopic structure of low carbon steel used for electrochemical studies X500

\section{Corrosion inhibitors}

The inhibitors used in the experiments were:

(i) 3DT177, 3DT179 (Nalco Products)

Physical Chemical Properties:

- clear, light yellow liquid

- slight acidic odor

- miscible in water

- $\mathrm{pH} 3.1$

- vapor pressure $15.6 \mathrm{~mm} \mathrm{Hg}$ at $100{ }^{\circ} \mathrm{F} / 20^{\circ} \mathrm{C}$

(ii) Galoryl IC $20 \mathrm{EU}$ is an aqueous anionic solution of organic and inorganic additives specifically developed as a corrosion inhibitor in fertilizer industries.

Typical properties:

- physical appearance, yellow liquid

$-\mathrm{pH} 9.0$

- specific gravity $\left(25^{\circ} \mathrm{C}\right), 1.03$ 
The inhibitors were dissolved in the corrosive solution at different concentrations: $0.2 \mathrm{~mL} / \mathrm{L}, 0.4 \mathrm{~mL} / \mathrm{L}, 0.6 \mathrm{~mL} / \mathrm{L} 0.8 \mathrm{~mL} / \mathrm{L}, 1.2 \mathrm{~mL} / \mathrm{L}$.

\section{Experimental investigation}

The electrochemical corrosion measurements were performed on a PC - controlled electrochemical analyzer PAR 2273 (Princeton Applied Research, USA) using a three electrodes cell containing a working electrode (steel), a saturated calomel electrode (ECS) as reference electrode and a platinum counter electrode. The electrolyte solution for corrosion measurements prepared conform Table 3, was acidic $(\mathrm{pH}=3)$ and had high salinity.

Table 3. The composition of the "produced water" used in corrosion tests $(\mathrm{pH}=3)$

\begin{tabular}{|c|c|c|c|c|c|c|c|c|}
\hline Conc. & $\mathrm{Fe}^{3+}$ & $\mathbf{N i}^{2+}$ & $\mathbf{C u}^{2+}$ & $\mathbf{N a}^{+}$ & $\mathrm{K}^{+}$ & $\mathbf{S O}_{4}{ }^{2-}$ & $\mathrm{NO}^{-}$ & $\mathrm{Cl}^{-}$ \\
\hline $\mathrm{g} / \mathrm{L}$ & 0.02 & 0.006 & $0.1 \cdot 10^{-3}$ & 50 & 5.4 & 6.64 & $0.27 \cdot 10^{-3}$ & 77.09 \\
\hline
\end{tabular}

The open circuit potential for steel immersed in the corrosive solution was monitored during 1 hour. The EIS was then measured in the frequency range from $10 \mathrm{kHz}$ to $10 \mathrm{mHz}$ at 30 points with a disturbance voltage of \pm 10 $\mathrm{mV}$. The impedance data were fited with a $2 R Q$ equivalent electrical circuit, using the ZSimpWin V3.21 software.

After the EIS measurement was finished, polarization curves were recorded immediately by scanning in a potential range of $\pm 20 \mathrm{mV}$ and of \pm $200 \mathrm{mV}$ vs. open circuit potential, with a scan rate of $10 \mathrm{mV} / \mathrm{min}$. The testing temperature was kept at $20^{\circ} \mathrm{C}$.

\section{REFERENCES}

1. Y. Liu, B. Zhang, Y. Zhang, L. Ma, P. Yang, Engineering Failure Analysis, 2016, 60, 307.

2. T. Liu, Y. F. Cheng, M. Sharma, G. Voordouw, Journal of Petroleum Science and Engineering, 2017, 156, 451.

3. S.S.M. Tavares, J.M. Pardal, F.B. Mainier, H.R. da Igreja, E.S. Barbosa, C.R. Rodrigues, C. Barbosa, J.P. Pardal, Engineering Failure Analysis, 2016, 61, 100.

4. H. Gao, Q. Li, Y. Dai, F. Luo, H.X. Zhang, Corrosion Science, 2010, 52, 1603.

5. Y. Liu, Y. Zhang, J. Yuan, Engineering Failure Analysis, 2014, 45, 225. 
6. A. Venkatesan, P.C. Wankat, Desalination, 2017, 404, 328.

7. M. Finšgar, J. Jackson, Corrosion Science, 2014, 86, 17.

8. M.L. Walker, Method and Composition for Acidizing Subterranean Formations, in: US Patent 5,366,643, Halliburton Company, Duncan, Okla,1994.

9. P.C. Okafor, X. Liu, Y.G. Zheng, Corrosion Science, 2009, 51, 761.

10. D.A. Williams, P.K. Holifield, J.R. Looney, L.A. McDougall, Method of Inhibiting Corrosion in Acidizing Wells, in: US Patent 5,200,096, Exxon Chemicals Patents, Inc., Linden, N.J., 1993.

11. A. Ostovari, S.M. Hoseinieh, M. Peikari, S.R. Shadizadeh, S.J. Hashemi, Corrosion Science, 2009, 51, 1935.

12. A.K. Satapathy, G. Gunasekaran, S.C. Sahoo, K. Amit, P.V. Rodrigues, Corrosion Science, 2009, 51, 2848. 